Paidéia, 2003, 13(25), 41-58

\title{
AVALIAÇÃO DE AMBIENTES EDUCACIONAIS INFANTIS ${ }^{1}$
}

\author{
Mariana Almeida de Oliveira \\ Rosângela de Assis Furtado \\ Tatiana Noronha de Souza \\ Mara Ignez Campos-de-Carvalho ${ }^{2}$ \\ FFCLRP - Universidade de São Paulo
}

\begin{abstract}
Resumo: Dada a ausência de instrumentos brasileiros para avaliação de qualidade da educação infantil, desenvolvemos estudos com duas escalas norte-americanas (Early Childhood Environment Rating ScaleECERS e Infant/Toddler Environment Rating Scale-ITERS), examinando sua precisão à realidade brasileira. Cada item (ECERS-37; ITERS-35) é pontuado de 1 a 7, conforme instruções específicas, observadas durante atividades do grupo. Foram avaliadas turmas de instituições filantrópicas, municipais, privadas e universitária, obtendo-se: (1) índice de acordo entre dois avaliadores independentes acima de $85 \%$, indicando um nível satisfatório de precisão; (2) baixo nível de qualidade do atendimento nas redes filantrópica e municipal, nesta havendo melhor qualidade; (3) nível satisfatório de qualidade em pré-escolas privadas e alto nível na creche universitária. As escalas discriminaram os vários modelos de instituição, diferenciaram as turmas entre si e aspectos satisfatórios ou deficitários em cada turma, essencial para a proposição de mudanças, visando melhoria na qualidade do atendimento oferecido.
\end{abstract}

Palavras-chave: avaliação de qualidade; educação infantil; creches; pré-escolas

\section{ASSESSMENT OF EARLY CHILDHOOD EDUCATIONAL ENVIRONMENTS}

Abstract: Due to the lack of Brazilian instruments that assess the quality of childhood settings, studies that examined the reliability of two American scales (Early Childhood Environment Rating Scale-ECERS and Infant/Toddler Environment Rating Scale-ITERS) were conducted in Brazilian institutions. Each item of each scale (ECERS-37; ITERS-35) is rated from 1 to 7 according to specific instructions observed during group activities. Groupings from custodial, public, private and university institutions were assessed and obtained: (1) satisfactory inter-rater reliability (over 85\%); (2) low quality level of care in both public and custodial networks (public better than custodial care); (3) satisfactory quality level in private pre-schools and high level in the university institution. The scales discriminated among different institutional models, differentiated playrooms between each other, and pointed out deficient and satisfactory aspects in each playroom. These aspects are very important for planning improvements of the quality of education provided.

Key-words: quality assessment; early childhood education; day care centers; pre-schools

$\mathrm{O}$ atendimento de crianças pequenas em ambientes coletivos no Brasil, especialmente as advindas de população mais carente, por um longo tempo foi motivado pela filantropia, sendo de cunho assistencialista, com total ausência do Estado (Cam-

\footnotetext{
' Artigo recebido para publicação em 17/10/02, aceito em 16/12/02.

2 Endereço para correspondência: Mara Ignez Campos de Carvalho, Departamento de Psicologia e Educação, Faculdade de Filosofia, Ciências e Letras de Ribeirão Preto, USP, Av. Bandeirantes, 3900, Monte Algre, Ribeirão Preto, SP, Cep 14040-901, E-mail: Mara@ffclrp.usp.br
}

pos, 1992; Kuhlmann, 2000). Este caráter assistencialista permaneceu, mesmo após o início do processo de industrialização do país, no início do século $\mathrm{XX}$, quando estas instituições passaram a ser valorizadas pela classe empresarial por possibilitarem a liberação da mão-de-obra feminina para o trabalho em fábricas. A partir deste período, especialmente as creches vêm sendo cada vez mais reivindicadas pelos trabalhadores, passando o Estado a assumir, gradualmente, a responsabilidade de 
seu oferecimento; entretanto, até nos dias de hoje, existem instituições de atendimento a crianças de $0 \mathrm{a}$ 6 anos com cunho eminentemente assistencialista.

Culminando este processo, a Constituição de 1988 (Brasil, 1988) incluiu as creches no sistema educativo, as quais deixam de pertencer à rede de assistência social, sendo a educação infantil a etapa inicial do sistema educacional do país (Brasil, 1996). Tal fato abriu importantes perspectivas ao avanço de propostas educacionais que reconheçam as necessidades específicas das crianças nos programas destinados à faixa etária de $0 \mathrm{a} 6$ anos, procurando superar o caráter assistencialista predominante.

No entanto; os avanços legais da educação infantil brasileira entram em conflito com o tipo de atendimento tradicionalmente oferecido em nossas creches, principalmente à população carente. O Brasil encontra-se hoje diante do desafio da melhoria da qualidade do atendimento prestado a crianças de $0 \mathrm{a}$ 6 anos. Estudos sobre a qualidade do atendimento oferecido nestas instituições educacionais se fazem urgentes, especialmente em creches, levando-se em conta os seguintes aspectos (Campos, 1992; Campos-de-Carvalho \& Rossetti-Ferreira, 1993): 1) a rápida expansão destes equipamentos; 2) relativo controle governamental quanto a critérios de funcionamento; 3) profissionais sem qualificação; 4) faita de informação e treinamento dos profissionais; 5) excesso de trabalho diário dos profissionais, com baixa remuneração; 6) pouca verba oficial.

O crescimento internacional da área de educação de crianças pequenas tem reforçado a necessidade de um adequado planejamento da organização dos espaços em instituições coletivas, nas quais a criança pequena possa, independentemente de sua origem sócio-econômica, compartilhar experiências com a supervisão e cuidados de profissionais habilitados a proporcionar condições adequadias para o estabelecimento de inter-relações constitutivas de uma boa socialização e desenvolvimento infantil (Merisse, 1997; Rosemberg, 1995).

Atualmente, há uma preocupação crescente com a qualidade dos programas de educação infantil. Vários estudos vêm sendo desenvolvidos (Katz, 1998; Melhuish, 2001; Pascal \& Bertram, 1999; Tietze, Bairrão, Leal \& Rossbach, 1998; Tietze, Cryer, Bairrão, Palacios \& Wetzel, 1996), visando obter um panorama sobre a qualidade de atendimento oferecido, a fim de garantir condições adequadas para o desenvolvimento global da criança. Entretanto, a definição dos critérios - dimensões da experiência utilizadas para determinar a qualidade da experiência (Katz, 1998) - de uma avaliação de qualidade da educação infantil é um processo complexo. Katz (1998) delineia cinco diferentes perspectivas para determinar a qualidade do atendimento oferecido, sendo os critérios da avaliação específicos a cada uma delas. Cada uma destas cinco perspectivas contribuem para uma avaliação global da qualidade de um programa: perspectiva dos adultos que elaboram e/ou aprovam o programa; abordagem baseada na experiência vivida pelas crianças; avaliação do programa experienciado pelas famílias atendidas; perspectiva que avalia o programa experienciado pelos educadores; abordagem pela qual se avalia as formas que o programa serve a comunidade e a sociedade. Embora concordemos com Katz (1998, p. 16) que uma "avaliação da qualidade de um programa através de perspectivas múltiplas coloca problemas complexos quanto às causas da má qualidade e à definição das responsabilidades por esse resultado", não cabe aqui uma discussão de cada uma dessas abordagens.

Apesar de qualidade ser um conceito construído e dinâmico (Pascal \& Bertram, 1999; Piotto \& Cols., 1998), há um consenso entre profissionais e pesquisadores (Pascal \& Bertram, 1999; Tietze \& Cols., 1998, 1996) sobre um conjunto de condições essenciais para a promoção de qualidade na educação infantil. Estas condições são as consideradas na primeira perspectiva delineada por Katz (1998) para a avaliação de programas de educação infantil: a proporção adulto/criança, o número de crianças por turma, a formação dos profissionais, a taxa de rotatividade dos profissionais, relações entre adultos e crianças, cuidados de saúde e higiene, prevenção de incêndios, etc..Estes aspectos, por serem diretamente observáveis e quantificáveis, são úteis como estratégias para a regulamentação do programa (Katz, 1998).

Estas condições podem ser examinadas por instrumentos adequados, especialmente aqueles que não têm uma base excessivamente cultural. Cada país, ocidental industrializado, tem tradições e culturas que 
são similares o suficiente para permitir o uso dos mesmos instrumentos, mas também "diversos o suficiente para se esperar diferenças em relação ao processo atual de qualidade produzido nos programas de cuidado e educação infantil" (Tietze \& Cols., 1996, p. 451).

A Early Childhood Environment Rating Scale - ECERS (Harms \& Clifford, 1980), desenvolvida nos Estados Unidos, tem sido um dos instrumentos utilizados internacionalmente para avaliar a qualidade do atendimento oferecido em instituições educacionais para crianças de 0 a 6 anos. Seus 37 itens são organizados em sete sub-escalas: Cuidados Pessoais, Materiais e Mobiliário para as Crianças, Experiências de Linguagem e Raciocínio, Atividades de Motricidade Global e Fina, Atividades Criativas, Desenvolvimento Social, Necessidades do Adulto.

A partir da ECERS foi desenvolvida a Infant/ Toddler Environment Rating Scale -ITERS (Harms, Cryer, \& Clifford, 1990), específica para avaliar ambientes coletivos para crianças de até 30 meses de idade. Seus 35 itens são agrupados em sete sub-escalas: Material e Mobiliário, Rotinas e Cuidados Pessoais, Linguagem Oral e Compreensão, Atividades de Aprendizagem, Interação, Estrutura do Programa e Necessidades do Adulto.

Apesar de não haver uma explicitação da concepção de qualidade dos autores no manual de ambas as escalas, esta se encontra implícita, em nossa opinião, nos critérios utilizados pelos autores, especificados em seus itens. Estes abrangem condições ou aspectos do atendimento oferecido, em sua grande maioria diretamente observáveis e quantificáveis, permitindo-nos identificar este tipo de avaliação como pertencente à primeira perspectiva apontada por Katz (1998). A concepção de qualidade implícita nas escalas é ampla o suficiente para avaliar diferentes tipos de propostas pedagógicas, delineando critérios que especificam altos padrōes de qualidade no atendimento a ser oferecido por qualquer tipo de instituição.

Ambas as escalas (ECERS e ITERS), através de seus itens, definem critérios de qualidade, sendo que cada item engloba um aspecto ou dimensão do ambiente oferecido em instituições educacionais infantis, tal como organização do espaço, interação, atividades, planejamento para crianças e provisões para a equipe e pais. Podem ser aplicadas em qualquer instituição que ofereça cuidados infantis; o avaliador pode ser da própria instituição (educadores, diretores e supervisores) ou de uma equipe de agência de assessoria. $\mathrm{O}$ aplicador deve observar uma turma por vez, durante o desenvolvimento de atividades pelo grupo de crianças e educadoras, por um período não inferior a duas horas. Análises de precisão e de validade de ambas as escalas apresentaram bons resultados (Harms \& Clifford, 1980; Harms, Cryer \& Clifford, 1990).

Considerando a ausência de instrumentos brasileiros, até onde temos conhecimento, para avaliação de qualidade do atendimento oferecido em instituições coletivas de crianças de 0-6 anos, Furtado (Furtado, 2001; Furtado \& Campos-de-Carvalho, 2000) desenvolveu um estudo exploratório com a ECERS, com o objetivo de iniciar o processo de verificar sua precisão e sua validação em nosso contexto sócio-cultural. A ECERS foi aplicada em 19 turmas de crianças de 4 a 6 anos, em pré-escolas municịpais, filantrópicas e privadas de Ribeirão Preto (SP). Oliveira (2000) desenvolveu um estudo inicial com a ITERS, traduzindo-a e aplicando-a em quatro turmas de creches filantrópicas e em seis de creches municipais, da cidade de Ribeirão Preto (SP), para dar início ao processo de examinar sua precisão. Souza (2002), dando continuidade a este estudo inicial com a ITERS, aplicou-a em 32 turmas de creches filantrópicas, municipais e universitária, de Ribeirão Preto (SP), visando continuar a verificação da precisão da escala e iniciando o processo de examinar sua validação em nosso contexto sócio-cultural. Enquanto validade refere-se ao grau pelo qual um instrumento mede o que se propõe a medir, o conceito de fidedignidade ou precisão refere-se à consistência de um instrumento de medida ao longo do tempo, ou ao longo de um conjunto de itens apresentados em uma mesma ocasião (Batista, 1996; Dessen \& Murta, 1997; Pasquali, 1996; Weick, 1968).

O presente artigo reúne o estudo de Furtado (2001) com a ECERS e os estudos de Oliveira (2000) e Souza (2002) com a ITERS, com o objetivo de apresentar os dados obtidos com as análises da precisão de ambas as escalas, utilizando o índice de concordância entre dois avaliadores independentes. Este índice é uma das formas de aferir a fidedignidade da 


\section{Mariana Almeida de Oliveira}

escala, ou seja, quando se tem interesse em determinar se o instrumento avalia ambientes consistentemente (Batista, 1996; Dessen \& Murta, 1997; Harms \& Clifford, 1980; Pasquali, 1996; Weick, 1968).

\section{Método}

\section{Populaçâo observada}

A ITERS foi aplicada em 42 turmas de creches de Ribeirão Preto (SP), onze delas pertencentes a creches filantrópicas, 28 a rede de creches municipais e três turmas da creche universitária do Campus da USP, tida como modelo dado seu alto padrão de qualidade no atendimento oferecido ${ }^{1}$. A idade das crianças variou de 6 a 38 meses e a maioria das turmas observadas contava com uma educadora e uma assistente. As creches funcionam em período integral e atendem população de baixa renda, sendo que a creche universitária atende filhos de funcionários, alunos e docentes do Campus de Ribeirão Preto.

A ECERS foi aplicada em 19 turmas de préescolas de Ribeirão Preto (SP), três delas de institui- ções privadas, duas filantrópicas e 14 municipais. A idade das crianças variou de $4 \mathrm{a} 6$ anos e, de um modo geral, havia uma professora em cada turma. As préescolas municipais e privadas funcionam em período parcial e as filantrópicas, em período integral; as municipais atendem população de média e baixa ren$\mathrm{da}$, as filantrópicas, de baixa renda e as privadas, de alta renda.

\section{Material}

A escala norte-americana Infant/Toddler Environment Rating Scale - ITERS (Harms \& Cols., 1990), traduzida por Oliveira (2000) e denominada neste estudo de Escala de Avaliação de Ambientes Coletivos para Crianças de 0-30 meses, consta de 35 itens agrupados em sete sub-escalas. A Early Childhood Environment Rating Scale - ECERS (Harms \& Clifford, 1980), aqui denominada de Escala de Avaliação do Ambiente Oferecido a Crianças Pequenas, é composta por 37 itens agrupados em sete sub-escalas. O Quadro 1 apresenta uma descrição resumida das sub-escalas e seus itens, de ambas as escalas.

Quadro 1: Descrição das 7 sub-escalas da ITERS e da ECERS.

\begin{tabular}{|c|c|}
\hline \multicolumn{2}{|c|}{$\begin{array}{c}\text { ROTINAS/CUIDADOS PESSOAIS: abrange todas as rotinas associadas ao conforto, } \\
\text { saúde e bem-estar das crianfas }\end{array}$} \\
\hline ITERS (9 itens) & ECERS (5 itens) \\
\hline $\begin{array}{l}\text { - Organização da chegada/saída } \\
\text { - Refeições/merendas } \\
\text { - Sono } \\
\text { - Condições de higiene } \\
\text { - Cuidados pessoais } \\
\text { - Práticas de condições de saúde } \\
\text { - Regulamentação das condições de saúde } \\
\text { - Práticas de condições de segurança } \\
\text { - Regulamentação das condições de segurança }\end{array}$ & $\begin{array}{l}\text { - Organização da chegadalsaida } \\
\text { - Refeiçōes/merendas } \\
\text { - Sonoldescanso } \\
\text { - Condições de higiene } \\
\text { - Cuidados pessoais }\end{array}$ \\
\hline
\end{tabular}

\begin{tabular}{l|l}
\hline \multicolumn{2}{c}{$\begin{array}{c}\text { MATERIAL / MOBILIÁRIO PARA AS CRIANÇAS: refere-se à forma de organização, de } \\
\text { manutercão e de uso do espaço, do material e do mobliliário }\end{array}$} \\
\hline \multicolumn{1}{c}{ ITERS (5 itens) } & \multicolumn{1}{c}{ ECERS (5 itens) } \\
\hline - Para cuidados de rotina & - Para atividades de rotina \\
- Para atividades de aprendizagem & - Para atividades de aprendizagem \\
- Para relaxamento e conforto & - Para descanso e conforto \\
- Arranjo da sala & - Arranjo da sala \\
- Exposição de materiais & - Exposição de materiais
\end{tabular}

\footnotetext{
${ }^{1}$ A aplicação da escala nesta creche teve como principal objetivo a análise de validade, não inclusa neste artigo, mas os dados da avaliação estão aqui incluídos para permitir uma comparação entre os três modelos de instituiçס̄es.
} 


\begin{tabular}{|c|c|}
\hline \multicolumn{2}{|c|}{$\begin{array}{l}\text { LINGUAGEM ORAL E COMPREENSÃO: refere-se à forma como a educadora enfatiza a } \\
\text { comunicação oral e ao uso de materiais que promovem a linguagem }\end{array}$} \\
\hline ITERS ( 2 itens) & ECERS (4 itens) \\
\hline $\begin{array}{l}\text { - Uso informal da linguagem } \\
\text { - Livros e figuras }\end{array}$ & $\begin{array}{l}\text { - Compreensão da linguagem } \\
\text { - Utilização da linguagem } \\
\text { - Utilização de conceitos aprendidos } \\
\text { - Uso informal da linguagem }\end{array}$ \\
\hline
\end{tabular}

\begin{tabular}{l|l}
\hline \multicolumn{2}{c}{$\begin{array}{c}\text { ATIVIDADES DE APRENDIZAGEM: atividades que exercitam a motricidade fina e global. Na } \\
\text { ITERS também inclui atividades de música, arte e faz-de-conta }\end{array}$} \\
\hline \multicolumn{1}{c|}{ ITERS (8 itens) } & \multicolumn{1}{c}{ ECERS (6 itens) } \\
\hline - Coordenação viso-motora & - Materiais de motricidade global e fina \\
- Atividade física & - Supervisão de atividades de motricidade fina \\
- Arte & - Espaço para motricidade global \\
- Música e movimento & - Tempo destinado para atividades de motricidade global \\
- Blocos/materiais de construção & - Supervisão de atividades de motricidade global. \\
- Faz-de-conta & \\
- Areia/água & \\
- Perspectiva multicultural &
\end{tabular}

INTERAÇÃO: refere-se à forma como ocorre a interação adulto-criança e como a educadora

\begin{tabular}{|c|c|}
\hline ITERS (3 itens) & ECERS (6 itens) \\
\hline $\begin{array}{l}\text { - Interação criança-criança } \\
\text { - Interação adulto-criança } \\
\text { - Disciplina }\end{array}$ & $\begin{array}{l}\text { - Espaço para estar sozinho } \\
\text { - Atividade livre } \\
\text { - Tempo em grupo } \\
\text { - Perspectiva multicultural } \\
\text { - Qualidade da interação } \\
\text { - Adequação para crianças com necessidades específicas }\end{array}$ \\
\hline
\end{tabular}

\begin{tabular}{l|l}
\hline \multicolumn{2}{c}{$\begin{array}{c}\text { NECESSIDADES DO ADULTO: abrange a presença de espaços e equipamentos para os adultos } \\
\text { (pais e educadores) e atendimento de suas necessidades }\end{array}$} \\
\hline \multicolumn{1}{c}{ [TERS (4 itens) } & \multicolumn{1}{c}{ ECERS (4 itens) } \\
\hline - Necessidades do pessoais do adulto & - Área do adulto \\
- Oportunidades para crescimento profissional & - Oportunidade de desenvolvimento profissional \\
- Área de encontro de adultos & -Área de encontros de adultos \\
- Medidas para envol vimento dos pais & - Envolvimentos dos pais
\end{tabular}

\begin{tabular}{l|l}
\hline \multicolumn{2}{c}{ ESTRUTURA DO PROGRAMA: refere-se ao planejamento e supervisão } \\
das atividades de aprendizagem \\
\hline \multicolumn{1}{c}{ ITERS (4 itens) } \\
\hline - Programa de atividades diárias \\
- Supervisão de atividades diárias \\
- Cooperação entre a equipe \\
- Adequação para crianças c/ necessidades \\
específicas
\end{tabular}

\begin{tabular}{|c|c|}
\hline \multicolumn{2}{|c|}{$\begin{array}{c}\text { ATIVIDADES CRIATIVAS: refere-se às atividades que permitem um uso construtivo } \\
\text { e flexível dos materiais }\end{array}$} \\
\hline & \begin{tabular}{|l|} 
ECERS (7 itens) \\
\end{tabular} \\
\hline$\because$ & $\begin{array}{l}\text { - Artes plásticas } \\
\text { - Música/movimento } \\
\text {-Blocos/materiais de construção } \\
\text { - Areia/água } \\
\text { - Jogo dramático } \\
\text { - Horário } \\
\text { - Supervisão }\end{array}$ \\
\hline
\end{tabular}




\section{Mariana Almeida de Oliveira}

Durante a aplicação das escalas, os observadores utilizavam uma cópia da escala traduzida e protocolos de registro, propostos nas escalas originais para anotações de cada item observado.

\section{Coleta de dados e local}

Anterior à aplicação das escalas, eram feitas visitas à instituição para explicitar à coordenadora o objetivo do estudo e obter consentimento para sua realização; nestas visitas iniciais, obtinha-se informações gerais para que os avaliadores tivessem um certo conhecimento da instituição. Em seguida, cada educador assinava um termo de consentimento em participar do estudo, bem como cada pai/mãe ou responsável por cada criança integrante da turma a ser avaliada.

A aplicação, com duração mínima de duas horas, foi realizada durante as atividades do educador com as crianças, tanto no interior das salas utilizadas pelos grupos, como nas demais dependências da instituição, conforme indicações em ambas as escalas. $\mathrm{O}$ aplicador observava um grupo de crianças por vez, permanecendo no local das atividades sem interferir ou participar das mesmas; quando necessário, complementava suas observações com entrevistas com a educadora e/ou outro membro da equipe, ra sua grande maioria já previstas nas escalas para esclarecimentos de certos aspectos.

As descrições contidas em cada item das escalas direcionavam as observações, possibilitando a escolha do escore em uma escala de 1 a 7 - (1) inadequado, (3) mínimo, (5) bom e (7) excelente. Qualquer um destes quatro escores só pode ser atribuído quando todas as condições descritas na escala estiverem presentes, com exceção da pontuação 1, a qual é dada se qualquer parte da descrição se aplica à situação observada. As pontuações intermediárias - 2, 4 e 6 são utilizadas quando estão presentes todas as condições da pontuação inferior e pelo menos a metade das condições da pontuação superior - este critério já estava assim descrito na versão original da ITERS, mas não nas instruções norte-americanas da ECERS. Nesta, consta a verificação da presença de algumas das condições para a pontuação superior. Para tornar mais preciso o termo algumas, foi utilizado nas aplicações o mesmo critério já presente na ITERS.
Em geral, a decisão do escore a ser atribuído para cada item da escala era tomada simultaneamente à observação do grupo, sendo então circulada a pontuação referente no protocolo de observação; anotações da situação observada, no protocolo, poderiam ou não ser feitas, a critério do observador. Porém, sempre eram feitas quando: 1) o aplicador necessitava de observações posteriores para pontuar alguns itens (por exemplo, os que envolviam interações); ou quando necessitava de mais reflexão para comparar as condições indicadas na escala e a situação observada (ocorrência mais freqüente nas primeiras aplicações do material); 2) o item previa, além da observação, esclarecimentos com algum mẹmbro da equipe.

\section{Procedimento}

\section{Etapa de tradução das escalas}

Inicialmente as duas escalas foram traduzidas, sendo que a ITERS diretamente do inglês para o português (Oliveira, 2000), enquanto que, para a ECERS, utilizou-se uma tradução feita em Portugal (Bairrão, 1997). Nesta etapa inicial já foram introduzidos termos mais apropriados ao contexto brasileiro, tal como na ECERS, escaninho no lugar do termo português cacifo. Na ITERS, ainda foram realizadas algumas adaptações de aspectos relativos a condições climáticas e referentes a materiais específicos: colchonetes poderiam substituir tanto camas/berços (item 1 Mobiliário para cuidados de rotina) como tapetes (item 3 - Mobiliário para relaxamento e conforto), uma vez que são muito utilizados em nosso contexto, independentemente das condições econômicas da instituição; decidiu-se que o uso de água quente (item 4 - Arranjo da turma; item 9 - Condições de higiene) seria exigido somente na presença de clima frio. Como já apontado, na ECERS foi também introduzido um critério mais objetivo nas instruções para atribuição dos escores intermediários. Tais alterações, entretanto, não alteraram a estrutura e conteúdo da ITERS e ECERS.

\section{Etapa de treinamento e familiarização com as es- calas}

Anteriormente e durante as aplicações das escalas nesta etapa, foram realizadas leituras e discus- 
sões sobre as escalas (tanto da versão traduzida como da original), para esclarecimentos de possíveis dúvidas sobre o material e, após a obtenção do índice de concordância inter-avaliadores, para discussão das discordâncias observadas e decisão do escore final a ser atribuído nos itens onde ocorreram desacordos. As alunas-pesquisadoras envolvidas em cada um dos três estudos aqui relatados, participaram dessas reuniões e duas delas tinham bastante experiência como educadoras. Em cada estudo, uma delas participava como a segunda avaliadora no outro trabalho, com exceção do estudo de Oliveira (2000), no qual o segundo avaliador foi uma mestranda do mesmo grupo de pesquisa, com treino de observação, mas investigando outro objeto de estudo (organização espacial em creches); esta avaliadora procedẹu à leitura e participou das discussões da ITERS.

Nesta etapa, a ITERS foi aplicada em onze turmas de creches filantrópicas e a ECERS em nove turmas de pré-escolas (três privadas, duas filantrópicas e quatro municipais). Para decidir o término da etapa de treinamento, foi proposta a obtenção de um critério mínimo de $70 \%$ de acordo entre dois avaliadores independentes, pois a concordância entre observadores é largamente utilizada para verificar a credibilidade e consistência dos dados observados, sendo muito útil numa fase de treinamento do observador (Dessen \& Murta, 1997; Sommer \& Sommer, 1997).

A avaliação foi feita independentemente pelas duas observadoras, estando ambas presentes no momento de observação de cada turma, em seis creches filantrópicas avaliadas pela ITERS e em todas as nove turmas avaliadas pela ECERS.

\section{Etapa de verificação da precisão das escalas}

Nesta etapa, decidiu-se que a aplicação das escalas ocorreria em turmas da rede municipal, a fim de uniformizar a amostra em função de controle metodológico, dadas certas características comuns exigidas pela Secretaria de Educação de Ribeirão Preto (por exemplo: nível de formação; participação em treinamentos; baixa rotatividade da equipe, etc.). A ITERS foi aplicada em 28 turmas e a ECERS em dez.

Quanto à ITERS, além do teste de acordo realizado em seis turmas para decidir o final da etapa de treinamento do observador, foram feitos dois novos testes de acordo entre dois avaliadores independentes, primeiramente em duas turmas e posteriormente em quatro. Considerando estes três momentos, os testes de acordo inter-avaliadores foram realizados em 12 das 42 turmas avaliadas (29\%). Quanto à ECERS, aquela verificação foi feita em nove das 19 turmas avaliadas $(47 \%)$.

\section{Análise dos dados}

A precisão de cada uma das duas escalas foi aferida através da análise da concordância dos escores atribuídos independentemente por dois observadores, presentes no mesmo momento de observação. Em cada turma avaliada, computou-se, item por item, a presença de acordo ou desacordo quanto ao escore atribuído por cada uma das avaliadoras, permitindo o cálculo da porcentagem de acordo quanto aos escores atribuídos, tanto para cada turma separadamente como considerando o conjunto delas. Um índice de acordo entre observadores igual ou superior a $70 \%$, tem sido indicado como satisfatório (Weick, 1968; Weiner, 1991).

Para cada turma avaliada, foi computado o escore obtido em cada sub-escala (soma dos escores atribuídos a cada um dos itens componentes daquela sub-escala) e o escore total obtido na escala (soma dos escores obtidos em cada sub-escala). Para cada sub-escala, foi calculado o valor dos escores mínimo e máximo possível de ser obtido (respectivamente, o número de itens multiplicado por 1 , pontuação mínima, e por 7, pontuação máxima). Estes valores não são os mesmos em cada sub-escala, devido à variação no número de itens em cada sub-escala e à eliminação de itens, prevista nas instruções das escalas. No total de 42 turmas avaliadas pela ITERS, em apenas duas não houve exclusão de itens. A exclusão mais freqüente foi do item 31 (Adequação para crianças com necessidades especiais - sub-escala VI Estrutura do programa), visto que as instituições não tinham crianças com tais características. Nas 19 turmas avaliadas pela ECERS, em apenas duas não houve a exclusão do item 3 (Sono / descanso - sub-escala I - Rotinas e cuidados pessoais), pois funcionavam em período integral.

Os sete pontos possíveis de serem atribuídos 


\section{Mariana Almeida de Oliveira}

a cada item, foram agrupados em três níveis distintos de qualidade (Bairrão, Leal, Abreu-Lima \& Morgado, 1997): 1) escores 1 e 2, indicadores de um nível baixo de qualidade; 2 ) escores 3 e 4 , indicadores de um nível satisfatório de qualidade; 3 ) escores 5 a 7 , indicadores de um nível alto de qualidade. Foi calculada a freqüência com que estes três grupos de escores foram atribuídos nas turmas avaliadas.

\section{Resultados}

\section{Precisão das escalas}

Os testes de concordância inter-avaliadores com a ITERS foram realizados em duas etapas, como já descrito na secção anterior. Desde que o índice de acordo obtido na etapa de treinamento foi satisfatório $(83 \%)$ e desde que os mesmos critérios foram utili- zados para a atribuição de escores nas duas etapas (de treinamento e de precisão), o teste de acordo da etapa de treinamento também foi utilizado para indicar a consistência da escala. $\mathrm{Na}$ etapa de precisão, a concordância entre os mesmos avaliadores foi de $91 \%$.

Desta maneira, considerando os testes de acordo nas duas etapas, num total de 393 itens avaliados pela ITERS (12 turmas), o índice de acordo entre os dois avaliadores independentes foi de $87 \%$. Os desacordos ocorreram em 19 itens, salientando-se sete deles pelo maior número de desacordos ocorridos nas duas etapas, com exceção dos desacordos do item 23 , que ocorreram apenas no primeiro teste de acordo. A Tabela 1 apresenta estes sete itens, juntamente com sua freqüência e porcentagem de ocorrência nas turmas onde o teste de acordo foi feito.

Tabela 1: Frequiência (entre parênteses) e porcentagem de desacordos entre dois avaliadores independentes, na aplicação da ITERS e da ECERS

\begin{tabular}{lc}
\hline \multicolumn{1}{c}{ ITERS } & Desacordos / Sub-escala \\
\hline 6- Organização da chegada e saída / II & (6) $50 \%$ \\
1 - Mobiliário para cuidados de rotina / I & (5) $42 \%$ \\
15- Uso informal da linguagem / III & (4) $33 \%$ \\
18- Atividade Física / IV & (4) $33 \%$ \\
23- Areia/água / IV & (4) $33 \%$ \\
13 - Prática de condições de segurança / II & (3) $25 \%$ \\
26- Interação adulto-criança / V & (3) $25 \%$ \\
\multicolumn{1}{c}{ ECERS } & Desacordos \\
\hline \multicolumn{1}{c}{ Item/ Sub-escala } & (3) $33 \%$ \\
7- Atividades de Aprendizagem / II & (3) $33 \%$ \\
\hline
\end{tabular}

Os demais desacordos observados em 12 itens, ocorreram com baixa frequiência e geralmente apenas em uma das etapas; em oito itens os desacordos ocorreram em duas das 12 turmas, dispersos por seis sub-escalas: itens $2,5,7,8,19,25,29$ e 32 ( 2 e 5 , da sub-escala I - Material e mobiliário para as crianças; 7 e 8, da sub-escala II - Rotinas e cuidados pessoais; os outros quatro itens pertencem cada um a uma subescala diferente); os desacordos restantes, em quatro itens, ocorreram somente em uma turma (itens 3,12 , 22 e 30 , cada um deles pertencentes a uma sub-escala diferente).

Para a ECERS, o teste de acordo entre dois avaliadores independentes foi realizado em nove turmas de pré-escolas (três privadas, duas filantrópicas e quatro municipais), sendo obtido $88 \%$ de acordo. De 326 itens avaliados, os desacordos ocorreram em 24 itens, entretanto salientando-se apenas dois deles, 
com ocorrência em três turmas, conforme apresentado na Tabela 1. Os desacordos nos demais 22 itens ocorreram, nove deles, apenas em duas das nove turmas, distribuídos por cinco sub-escalas: itens 5, 11, $16,20,23,24,26,28$ e $30(23,24$ e 26 pertencentes à mesma sub-escala V - Atividades criativas; 16 e 20, da sub-escala IV - Atividade de motricidade global e fina; 28 e 30 , da sub-escala VI - Desenvolvimento social; os outros dois itens -5 e 11 - pertencem, cada um, a uma sub-escala diferente). Os desacordos nos 13 itens restantes ocorreram somente em uma turma, dispersos por seis sub-escalas: itens $1,2,4,10,14$, $15,18,19,20,29,32,33$ e $35(1,2$ e 4 , da sub-escala
I - Rotinas e cuidados pessoais; $15,18,19$ e 20, da sub-escala IV - Atividade de motricidade global e fina; 29,32 e 33, da sub-escala VI - Desenvolvimento social; cada um dos três itens restantes $-10,14 \mathrm{e}$ 35 - pertence a uma sub-escala diferente).

\section{Escores por sub-escalas}

Para ilustrar os dados obtidos por sub-escala com a aplicação da ITERS, a Figura 1 mostra esta distribuição para uma turma de cada um dos três tipos de instituições avaliadas (filantrópica, municipal e universitária). Pode-se ver a variação entre as subescalas quanto ao valor do menor e maior escore possível de ser obtido.

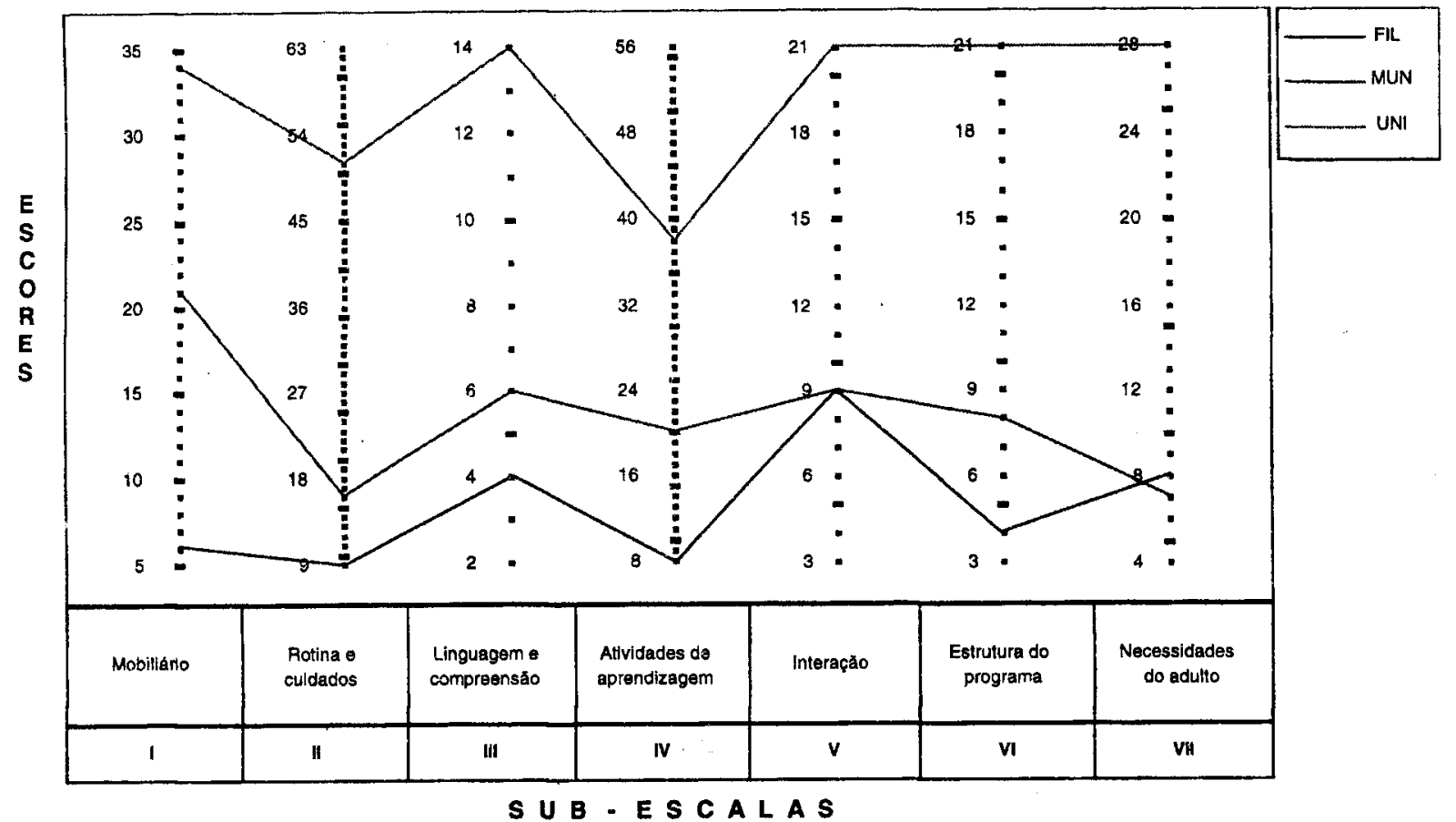

Figura 1: Escores obtidos por sub-escala da ITERS em três turmas, uma de cada tipo de creche avaliada (filantrópica, municipal e universitária).

Em relação aos escores obtidos em cada subescala, a Figura 1 mostra que, para a turma da creche filantrópica, a distribuição dos escores encontra-se na parte inferior da figura, indicaǹdo sua aproximação aos escores mínimos possíveis de serem obtidos. Mas há diferenças entre as sub-escalas: as que se salientaram, por apresentarem escores mais elevados, foram as sub-escalas V (Interação), III (Linguagem oral e compreensão) e VII (Necessidades do adulto), com destaque para a V; os escores mais baixos foram atribuídos às sub-escalas II (Rotinas e cuidados pessoais) e IV (Atividades de aprendizagem), atingindo o valor do menor escore possível de ser obtido.

Já na turma da creche municipal, a distribuição dos escores na parte central da Figura 1 indica um nível intermediário entre os escores mínimo e máximo possíveis de serem obtidos. Às seguintes subescalas foram atribuídas as pontuações mais altas 


\section{Mariana Almeida de Oliveira}

desta turma: I (Material e mobiliário para as crianças), III (Linguagem oral e compreensão) e V (Interação) destacando-se a I; os menores escores foram atribuídos às sub-escalas II (Rotinas e cuidados pessuais) e VII (Necessidades do adulto).

$\mathrm{Na}$ turma da creche universitária, os escores concentram-se na parte superior da Figura 1, indicando que a maioria dos escores atribuídos estavam bem próximos ou eram iguais aos escores máximos possíveis de serem obtidos. As outras duas turmas universitárias avaliadas apresentaram este mesmo padrão de pontuação, obtendo destaques, nas três turmas, as sub-escalas III (Linguagem oral e compreensão), V (Interação), VI (Estrutura do programa) e VII (Necessidades do adulto), por atingirem os escores mais elevados possíveis de serem obtidos; a pontuação da sub-escala I (Material e mobiliário para as crianças) está apenas um ponto abaixo do escore máximo. Às sub-escalas IV (Atividades de aprendizagem) e II (Rotinas e cuidados pessoais) foram atribuídos os escores mais baixos em cada uma das três turmas da creche universitária.

A grande maioria das turmas de instituições filantrópicas e municipais avaliadas pela ITERS, apresentou um padrão semelhante ao mostrado na Figura 1, quanto à distribuição de escores pelas subescalas. Dada a limitação de espaço, a seguir são salientados os aspectos comuns à maioria das turmas.

Comparando os resultados dos escores atribuídos para cada sub-escala nas 11 turmas filantrópicas avaliadas, verificou-se que a sub-escala II (Rotinas e cuidados pessoais) destacou-se por apresentar, em oito turmas (73\%), um dos escores mais baixos atribuídos, seguida pelas sub-escalas IV (Atividades de aprendizagem) e VI (Estrutura do programa), em seis turmas (55\%). As sub-escalas V (Interação) e VII (Necessidades do adulto) apresentaram, respectivamente em oito e sete turmas, um dos escores mais altos atribuídos. Interessante apontar que em nenhuma turma filantrópica, a sub-escala II (Rotinas e cuidados pessoais) salientou-se quanto à obtenção de escores mais altos.

Considerando os resultados dos escores atribuídos por sub-escala em cada uma das 28 turmas municipais, constatou-se que a sub-escala $\mathrm{V}$ (Interação) apresentou, em 21 turmas (75\%), um dos escores mais altos atribuídos, seguida pela sub-esca- la I (Material e mobiliário para as crianças), em 15 turmas (54\%). As sub-escalas II (Rotinas e cuidados pessoais) e IV (Atividades de aprendizagem) apresentaram, respectivamente em $16(57 \%)$ e 13 turmas (46\%), um dos escores mais baixos atribuídos; apenas em duas das 28 turmas municipais, a sub-escala II alcançou um dos escores mais altos.

Totalizando as 42 turmas avaliadas pela ITERS, verificou-se que três sub-escalas se destacaram por apresentarem um dos escores mais altos atribuídos: sub-escala V, em 32 das turmas ( $76 \%$ ), subescala I, em 23 turmas (55\%) e sub-escala VII, em 20 turmas $(48 \%)$. Em relação aos escores mais baixos atribuídos, destacaram-se as sub-escalas II (Rotinas e cuidados pessoais), em 27 turmas (64\%) e a IV (Atividades de aprendizagem), em 22 turmas (52\%).

Para ilustrar os dados obtidos por sub-escala com a aplicação da ECERS, a Figura 2 mostra esta distribuição para uma turma de cada um dos três tipos de instituições avaliadas (filantrópica, municipal e privada); pode-se ver a variação entre as subescalas quanto ao valor do menor e maior escore possível de ser obtido.

Em relação aos escores obtidos em cada subescala, a Figura 2 mostra que, para a turma da préescola filantrópica, há mais concentração de escores na parte inferior da figura, indicando que as pontuações atribuídas se aproximaram dos escores mínimos possíveis de serem obtidos em cada sub-escala. Mas há diferenças entre as sub-escalas: as que se salientaram, por apresentarem escores mais elevados, foram as sub-escalas IV (Atividade de motricidade global e fina) e I (Rotinas e cuidados pessoais), sobressaindo-se a IV; os escores mais baixos foram atribuídos às sub-escalas VII (Necessidades dos adultos) $e$ III (Experiências de linguagem e raciocínio), destacando-se a VII, à qual foi atribuída uma pontuação apenas um ponto acima do valor do menor escore possível de ser obtido. A outra turma filantrópica avaliada, apresentou mais sub-escalas com escores superiores que a turma apresentada na Figura 2, destacando-se a sub-escala V (Atividades criativas), a qual obteve o maior escore atribuído. Porém, há aspectos em comum às duas turmas: em ambas, a subescala VII (Necessidades dos adultos) apresentou o menor escore atribuído e a sub-escala I (Rotinas e 


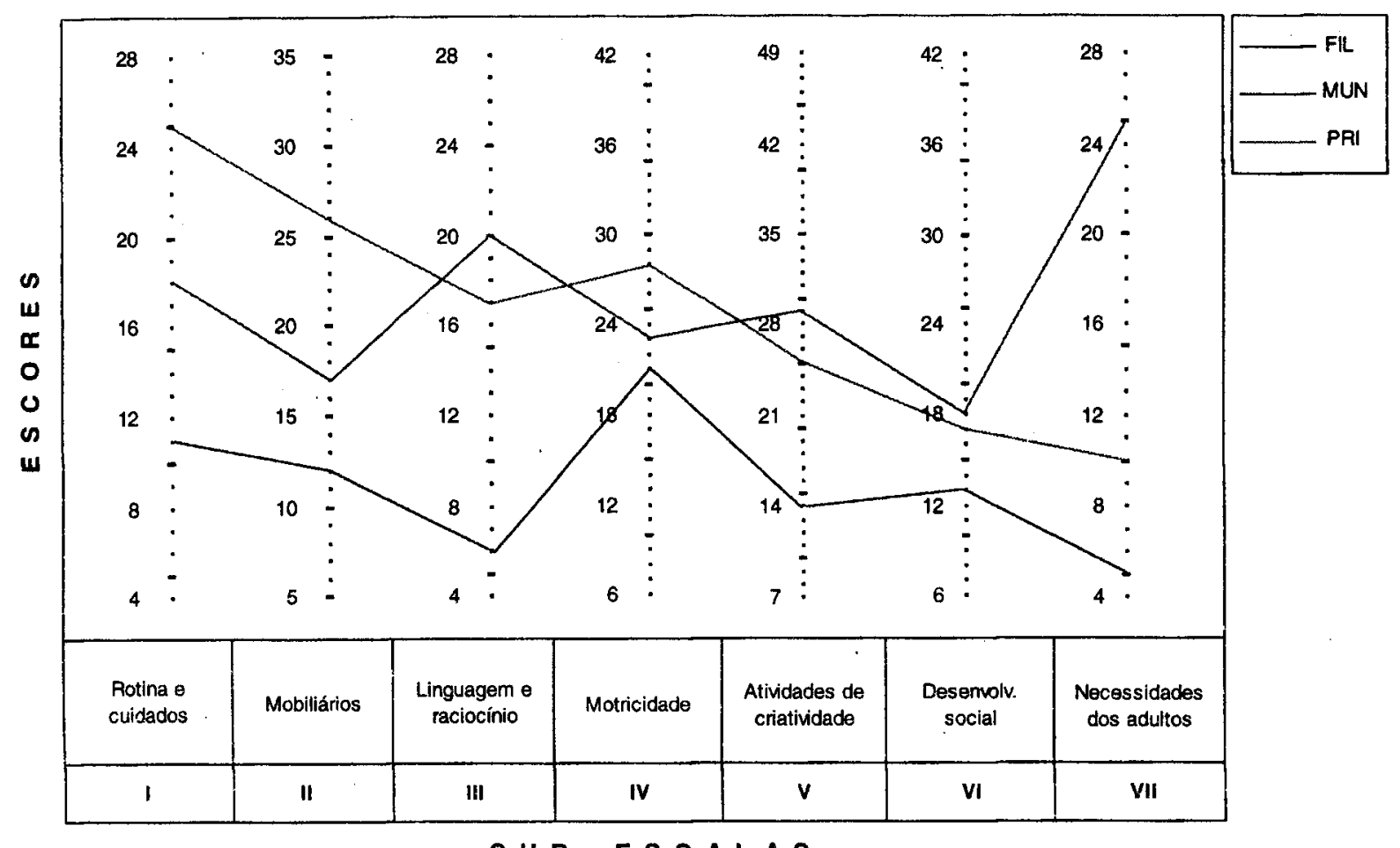

S UB - E S C A L A S

Figura 2: Escores obtidos por sub-escala da ECERS em três turmas, uma de cada tipo de instituição avaliada (filantrópica, municipal e privada).

cuidados pessoais), um dos mais altos.

Na turma da pré-escola privada, os escores que se encontram na parte superior da Figura 2, indicam sua proximidade com os escores máximos possíveis de serem obtidos; porém, a maioria dos escores atribuídos concentram-se na parte central, evidenciando um nivel intermediário entre os escores mínimo e máximo possíveis de serem obtidos. Às sub-escalas I (Rotinas e cuidados pessoais), II (Mobiliários e materiais para as crianças), IV (Atividades de motricidade global e fina) e III (Experiências de linguagem e raciocínio) foram atribuídos os maiores escores desta turma, salientando-se a I. Os menores escores foram atribuídos às sub-escalas VII (Necessidades dos adultos), VI (Desenvolvimento social) e V (Atividades criativas), destacando-se a VII. As duas outras turmas privadas apresentaram, no geral, o mesmo padrão, porém uma das turmàs obteve um número maior de sub-escalas com escores superiores. Considerando as três turmas em conjunto, verificou-se que em duas delas a sub-escala I (Rotinas e cuidados pessoais) obteve a pontuação mais alta; nas sub-es- calas III (Experiências de linguagem e raciocínio) e IV (Atividades de motricidade global e fina), observou-se um dos escores mais aitos atribuídos em cada uma das três turmas. Quanto às pontuações mais baixas, destacou-se a sub-escala VI (Desenvolvimento social) - nas três turmas aí se localizou o escore mais baixo atribuído - e, em seguida, a sub-escala $\mathrm{V}$ (Atividades criativas), em duas delas.

$\mathrm{Na}$ turma da pré-escola municipal, a grande concentração das pontuações na região central da Figura 2, indica um nível intermediário entre os escores mínimo e máximo possíveis de serem obtidos. Às seguintes sub-escalas foram atribuídas as pontuações mais altas desta turma: sub-escala VII (Necessidades dos adultos), III (Experiências de linguagem e raciocínio) e I (Rotinas e cuidados pessoais), destacando-se a VII (Necessidades dos adultos); os menores escores foram atribuídos às sub-escalas VI (Desenvolvimento social) e II (Mobiliários e materiais para as crianças), destacando-se a VI.

A grande maioria das 14 turmas avaliadas de instituições municipais apresentou um padrão seme- 


\section{Mariana Almeida de Oliveira}

lhante ao mostrado na Figura 2, quanto à distribuição de escores pelas sub-escalas. Dada a limitação de espaço, a seguir são salientados os aspectos comuns à maioria delas. Foi atribuída à sub-escala VII (Necessidades dos adultos) a pontuação mais alta em 11 turmas (78\%); em seguida, a sub-escala I (Rotinas e cuidados pessoais) apresentou em 10 turmas (71\%) um dos escores mais altos e a sub-escala III (Experiências de linguagem e raciocínio), em sete turmas (50\%). As sub-escalas VI (Desenvolvimento social) e II (Mobiliários e materiais para as crianças) apresentaram, respectivamente, em 13 (93\%) e oito turmas $(57 \%)$, um dos escores mais baixos atribuídos, chamando ainda atenção o fato de que não foi atribuído à sub-escala VI, em nenhuma das 14 turmas, escores mais altos.

Totalizando as 19 turmas avaliadas pela ECERS, verificou-se que três sub-escalas se destacaram por apresentarem um dos escores mais altos, considerando os escores atribuídos por sub-escala em cada uma das turmas: sub-escala I, em 14 turmas (74\%), sub-escala VII, em 12 turmas $(63 \%)$ e subescala III, em 11 turmas (76\%). Em relação aos escores mais baixos atribuídos, destacaram-se as sub-escalas VI (Desenvolvimento Social), em 17 turmas (89\%) e II (Mobiliários e materiais para as crianças), em nove turmas ( $47 \%$ ); a sub-escala VI salienta-se ainda por não ter obtido escores mais altos em nenhuma das 19 turmas avaliadas.

\section{Escores totais}

Desde que não seja excluído nenhum item, o escore total máximo possível de ser obtido na ITERS é de 245 e o mínimo 35 e na ECERS é 259 e 37.

Para a ITERS, o escore total obtido em cada uma das 11 turmas de creches filantrópicas avaliadas, permaneceu mais próximo do escore mínimo possível de ser obtido, sendo a amplitude de variação de 33 a 58 (mediana 48). Já os escores totais das 28 turmas municipais avaliadas, variaram de 34 a 117, cuja mediana (74) é superior à das creches filantrópicas. As três turmas avaliadas da creche universitária apresentaram escores sensivelmente superiores 197, 198 e 207 -, mais próximos do escore máximo possível de ser obtido.

Para a ECERS, os escores obtidos nas duas turmas filantrópicas avaliadas foram 87 e 112, portanto mais próximos do escore mínimo possível de ser obtido. A amplitude de variação dos escores totais obtidos nas 14 turmas municipais avaliadas, foi de 116 a 171 (mediana 136), situando-se, portanto, num nível intermediário entre os escores mínimo e máximo possíveis. Já os escores totais das três turmas privadas foram mais altos - 143, 148 e 175 -e mais próximos do escore máximo possível de ser obtido.

\section{Escores agrupados por niveis de qualidade}

A Tabela 2 mostra os escores obtidos na aplicação da ITERS e da ECERS, agrupados quanto aos níveis de qualidade.

Tabela 2: Frequiência $(\mathrm{F})$ e porcentagem $(\%)$ de distribuição dos escores atribuídos às instituições avaliadas pela ITERS e pela ECERS.

\begin{tabular}{|c|c|c|c|c|c|c|}
\hline \multirow[t]{3}{*}{ INSTITUIÇÃO } & \multicolumn{6}{|c|}{ ESCORES } \\
\hline & \multicolumn{2}{|c|}{$1-2$} & \multicolumn{2}{|c|}{ 3-4 } & \multicolumn{2}{|c|}{5 a 7} \\
\hline & $\mathbf{F}$ & $\%$ & F & $\%$ & $\mathbf{F}$ & $\%$ \\
\hline \multicolumn{7}{|l|}{ Filantrópica } \\
\hline ITERS & (321) & 87 & (49) & 13 & $(00)$ & 00 \\
\hline ECERS & (031) & 42 & (36) & 49 & $(07)$ & 09 \\
\hline \multicolumn{7}{|l|}{ Municipal } \\
\hline ITERS & (569) & 60 & (306) & 32 & (067) & 07 \\
\hline ECERS & (046) & 09 & (260) & 52 & (198) & 49 \\
\hline \multicolumn{7}{|l|}{ Universitária } \\
\hline ITERS & (10) & 10 & $(08)$ & 08 & $(82)$ & 82 \\
\hline Privada & & & & & & \\
\hline ECERS & $(15)$ & 14 & $(40)$ & 37 & (53) & 49 \\
\hline \multicolumn{7}{|l|}{ Total } \\
\hline ITERS & $(900)$ & 64 & (363) & 26 & (149) & 11 \\
\hline ECERS & (092) & 13 & (336) & 49 & (258) & 38 \\
\hline
\end{tabular}


Nas 11 turmas filantrópicas avaliadas pela ITERS, a maioria dos escores atribuídos concentraram-se nas pontuações inferiores 1 e $2(87 \%)$ e, em nenhuma das turmas, foi atribuída qualquer uma das pontuações superiores ( 5 a 7). As 28 turmas das creches municipais, embora com maior concentração de pontuações também nos escores inferiores $(60 \%)$, comparadas à rede filantrópica, apresentam um aumento sensível nas pontuações intermediárias 3 e 4 ( $32 \%$ contra $13 \%$ da rede filantrópica). Já os escores obtidos nas três turmas da creche universitária, indicam uma alta concentração (82\%) nas pontuações superiores ( 5 a 7) e uma baixa concentração nas pontuações intermediárias e inferiores.

Nas turmas de pré-escolas filantrópicas e municipais avaliadas pela ECERS, houve maior concentração de escores nas pontuações intermediárias ( $3 \mathrm{e}$ 4), $49 \%$ e $52 \%$, respectivamente. No entanto, nas turmas da rede municipal, a atribuição (39\%) de escores nas pontuações superiores é bèm maior do que na rede filantrópica (9\%). Chama atenção, ainda, a diferença observada na rede municipal, comparando as creches (avaliadas pela ITERS) e pré-escolas (ECERS), tendo as primeiras maior concentração de escores inferiores $(60 \%$ nas creches e $9 \%$ nas préescolas). Os escores atribuídos nas turmas das préescolas privadas, indicam uma concentração maior nas pontuações superiores $(49 \%)$ e intermediárias (37\%); houve pouca atribuição de escores inferiores, tal como observado nas turmas da creche universitária, avaliadas pela ITERS.

\section{Discussão}

Os testes de acordo entre dois avaliadores independentes, realizados com a ITERS e ECERS, apresentaram índices satisfatórios (Weick, 1968; Weiner, 1991), superiores a 85\%. Ademais, verificou-se pouca concentração de desacordos, ou seja, houve dispersão dos desacordos pelos vários itens. Ambos os aspectos fornecem uma forte indicação da precisão das escalas, quando sua consistência foi verificada pela atribuição de escores a cada item, por dois avaliadores independentes.

Os desacordos ocorreram especialmente em itens que permitem interpretações pessoais, pois as descrições contidas na escala são mais subjetivas, possibilitando que significados e concepções dos avaliadores exerçam influência na análise destas situações. Considerando os cinco tipos de perspectivas possíveis para se avaliar um programa de educação infantil (Katz, 1998), a primeira abordagem (na qual se encaixa a avaliação feita pelas duas escalas) considera aspectos que podem ser mais diretamente obșerváveis e quantificáveis.Entretanto, sempre há alguma exigência de inferência por parte do avaliador, embora em âmbitos relativamente restritos, em comparação às demais abordagens, como apontado por Katz (1998).

$\mathrm{Na}$ aplicação da ITERS, interpretações pessoais provavelmente ocorreram nos itens 6 (Organização de chegada e saída), 1 (Mobiliário para cuidados de rotina), 15 (Uso informal da linguagem), 18 (Atividade física) e 23 (Areia/Água). Quanto ao item 6 , a ocorrência dos desacordos provavelmente deveuse ao fato de serem observações de situações dinâmicas, ou seja, a chegada e saída de pais, muitas vezes vários ao mesmo tempo, o que possibilita a observação de diferentes aspectos, da mesma situação, por parte das avaliadoras. No item 1 , descrições do tipo "móveis em estado de conservação ruim" ou "em boin estado" permitiram diferentes interpretações por parte das avaliadoras, levando aos desacordos; a mesma explicação pode ser dada ao item 15 , com descrições do tipo "pouca conversa", "alguma resposta às tentativas de comunicação das crianças". Já no item 18, cujas descrições são mais objetivas, considerou-se a possibilidade de erro por parte de uma das avaliadoras. No item 23 , a escala indica que o tanque de areia deve ser coberto, mas não especifica qual o tipo de cobertura (possível causa de desacordo); por exemplo, em algumas creches municipais avaliadas, o tanque de areia é cercado por um alambrado, impedindo sua contaminação pela entrada de animais grandes - ocorreram desacordos na consideração se este alambrado seria adequado à exigência de cobertura pela escala. Entretanto, ainda nos questionamos se é aconselhável, ou não, tornar mais objetivas as descrições destes itens, especialmente as que envolvem situações dinâmicas, onde uma quantificação não abarcaria, necessariamente, a qualidade do que está sendo observado.

Na aplicação da ECERS, houve baixa concentração de desacordos nos itens 7 (Atividades de apren- 


\section{Mariana Almeida de Oliveira}

dizagem) e 8 (Descanso e conforto), da sub-escala II (Mobiliários e materiais para as crianças), provavelmente devido a interpretações diferentes dos observadores, em função da falta de objetividade na descrição das instruções para pontuações. Também houve ocorrência de desacordos na atribuição de pontuações intermediárias, devido não haver clareza suficiente nas instruções da escala original; como já apontado, após a verificação destes desacordos, introduzimos um critério mais objetivo nas instruções para atribuição dos escores intermediários.

Considerando os escores atribuídos nas turmas avaliadas, as creches e pré-escolas da rede filantrópica apresentaram os menores escores, próximos ao escore mínimo possível de ser obtido. Esta rede funciona em condições precárias, principalmente por dois motivos: à concepção assistencialista que ainda prevalece (Kuhlmann, 2000) e à falta de financiamento, avaliação, supervisão e assessoria por parte do poder público (Brasil, 1996; MEC, 1998). A rede filantrópica, especialmente as creches, não possui uma proposta pedagógica definida, baseada em concepçôes atuais de desenvolvimento. Isso se reflete na ausência de um programa estruturado, em uma rotina inflexível e com longos períodos de espera pelas crianças, sem nada para fazer (espera para banho, para alimentação, para usar um determinado brinquedo, etc.) e pela falta de conhecimento de atividades adequadas a serem oferecidas nesse período de 0 a 3 anos.

A rede municipal mostrou escores sensivelmente mais altos em relação à rede filantrópica, porém ainda com pontuações mais próximas aos menores escores possíveis de serem obtidos, principalmente no caso das creches. Deve-se considerar que as creches foram inseridas na rede educacional apenas a partir de 1996 (Brasil, 1996) e, atualmente, estão tendo que oferecer programa de formação de nível médio e em serviço aos educadores. Junto a isso, as creches municipais de Ribeirão Preto têm passado por uma adequação de seus espaços às necessidades das crianças, suas coordenadoras possuem formação superior e têm mais recursos financeiros que as filantrópicas - tais aspectos, por se refletirem na prática de atendimento, devem ter favorecido a atribuição de escores mais altos que na rede filantrópica.

Os escores atribuídos às turmas da creche uni- versitária, na avaliação pela ITERS, foram os mais altos possíveis de serem obtidos, ou próximos a eles. Esta creche conta com um processo de formação em serviço de seus educadores há cerca de 10 anos, os quais, em sua grande maioria, possuem o nível médio exigido pela LDB (Brasil, 1996); além disso, é mantida pelo poder público estadual, possuindo recursos financeiros maiores que as municipais e filantrópicas. Esta creche é tida como modelo no meio educacional brasileiro, dado seu alto padrão de qualidade no atendimento oferecido, aspecto este confirmado na avaliação das três turmas neste estudo. Apesar da possível influência do conhecimento desta informação pela avaliadora na escolha dos escores a serem atribuídos, salientamos que grande parte dos critérios de qualidade considerados na ITERS permitem uma observação e quantificação direta, requisitando um menor grau de inferência por parte do avaliador do que os demais tipos de perspectivas possíveis de avaliação de programas de educação infantil, como apontado por Katz (1998).

No conjunto das 42 turmas avaliadas pela ITERS, as sub-escalas que se destacaram por obterem escores mais altos foram a V-Interação, I-Material e mobiliário para as crianças (com exceção das turmas filantrópicas) e VII-Necessidades do adulto. Nas turmas filantrópicas, a sub-escala V, embora tenha se salientado em comparação às demais, permaneceu próxima ao menor escore possível de ser obtido. No caso das creches municipais, os escores levemente superiores da sub-escala $V$ em relação aos da filantrópica, podem refletir o processo de formação em nível médio e em serviço pelo qual os educadores têm passado; na creche universitária, os altos escores obtidos também refletem a formação oferecida aos educadores, com ênfase no desenvolvimento infantil ocorrendo através das interações com adultos e demais crianças. A pontuação mais alta da sub-escala VII nas turmas filantrópicas, pode refletir uma preocupação maior com o mobiliário para os adultos que para as crianças, mesmo que ainda estejam distantes dos padrões de alta qualidade indicados na escala. Já nas creches municipais e universitária, a preocupação com as necessidades dos adultos tanto quanto com as necessidades infantis (sub-escala I), é maior que nas filantrópicas, provavelmente por serem dirigidas por profissionais formados na área $e$ 
por possuírem maiores recursos financeiros. Ainda em relação à sub-escala I, é necessário apontar o fato que a rede municipal e a creche universitária fazem reposição e manutenção de todo o material, sempre que necessário (ainda que a rede municipal apresente, por vezes, problemas em relação aos recursos para reposição de brinquedos), o que muito raramente ocorre na rede filantrópica.

As pontuações mais baixas foram atribuídas às sub-escalas II-Rotina/cuidados pessoais e IVAtividades de aprendizagem. Em relação à II, nas creches municipais e filantrópicas observou-se omissões freqüentes do educador em relação à limpeza de nariz (rede municipal), ao lavar as mãos antes/pós as refeições (municipal) e troca de fraldas (municipal e universitária) e à substituição do lençol do local de troca de fraldas (municipal e universitária). Quanto à sub-escala IV, nas turmas filantrópicas observouse a existência de poucos brinquedos, sem variedade e em um estado ruim de conservação; na rede municipal há melhor conservação dos brinquedos, porém há pouca diversidade. Na creche universitária, o escore máximo não foi atingido por não haver certos materiais apontados pela escala, como por exemplo a presença de blocos e materiais de construção (item 21), porém possuindo outros que cumpriam a mesma função (tais como caixinhas de leite, copinhos plásticos, potes de yogurtes, latas, caixas de papelão, preferencialmente de vários tamanhos, inclusive permitindo que a criança entre neles). A possibilidade da presença de outros materiais com a mesma função dos indicados na escala, é uma provável modificação a ser incluída futuramente na escala.

Nas avaliações realizadas pela ECERS, as turmas filantrópicas também obtiveram escores próximos aos mais baixos. Esta rede, como já apontado, funciona em condições precárias, principalmente por falta de financiamento, avaliação, supervisão e assessoria por parte do poder público (Brasil, 1996; MEC, 1998). Apesar do caráter assistencialista, em instituições filantrópicas há alguma proposta educacional para as crianças acima de 4 anos, mesmo que seja visando uma preparação para a alfabetização, enquanto que para a faixa etária de 0 a 3 anos há, geralmente, uma ausência de proposta educacional. Tal fato se reflete diretamente nas avaliações realizadas pela ECERS, havendo maior atribuição de es- cores intermediários e superiores do que na ITERS, refletindo um melhor nível de qualidade do que o atendimento oferecido até os 3 anos, considerando qualquer um dos três modelos institucionais avaliados. A rede municipal, na avaliação pela ECERS, apresentou-se superior à filantrópica, demonstrando um nível satisfatório de qualidade em seu atendimento. Já nas avaliações realizadas pela ITERS, houve indicação predominante de um baixo nível de qualidade. Entretanto, as creches municipais apresentaram, em comparação às filantrópicas, um aumento de pontuações intermediárias, indicando uma amplitude maior de aspectos de seu atendimento classificados em um nível satisfatório de qualidade; isto provavelmente reflete um ganho já obtido com a inserção, embora tardia, das creches no sistema educacional, conseqüência dos investimentos já feitos nas creches municipais.

As turmas de pré-escolas privadas apresentaram, no geral, escores mais altos que as municipais e filantrópicas, mas ainda distantes dos escores máximos possíveis de serem obtidos. Houve aspectos de seu atendimento classificados em um nível alto de qualidade e outros em um nível satisfatório. Vale destacar que as turmas avaliadas eram de instituições conceituadas, atendendo a camada sócio-econômica alta, o que as diferencia da rede privada que está em expansão em bairros menos nobres, infelizmente funcionando em casas mal adaptadas (Góis, 2000) e clandestinamente, ou seja, sem serem regulamentadas pela secretaria de educação. As escolas das turmas avaliadas possuem recursos humanos e financeiros para a implantação de projetos educacionais, a população atendida em geral reivindica qualidade do ensino oferecido às crianças e, acima de tudo, por participarem de um mercado competitivo de escolas, necessitam oferecer um atendimento de qualidade.

No conjunto das 19 turmas avaliadas pela ECERS, estas são as sub-escalas que se destacaram por obterem os escores mais altos atribuídos: VIINecessidades do adulto, III-Experiências de linguagem e raciocínio e I-Rotina/cuidados pessoais.

Na sub-escala VII, observa-se que as pontuações mais altas foram atribuídas aos itens referentes à Área Pessoal do Adulto e Áreas de Encontro dos Adultos. Percebe-se que a grande maioria das préescolas valoriza estes espaços, com o objetivo de aten- 


\section{Mariana Almeida de Oliveira}

der as necessidades da equipe (por exemplo, oferecendo armários individuais, banheiros exclusivos, etc.), especialmente na rede pública. A sub-escala III avalia itens como a utilização de conceitos aprendidos, mais valorizados nas pré-escolas privadas; avalia também o uso informal da linguagem, em relação ao qual, nas turmas públicas, observou-se maior liberdade à expressão infantil e para a criança improvisar e propor atividades, possivelmente pela influência da perspectiva sócio-interacionista, muito discutida na rede pública de ensino (Furtado, 2001). Em relação à sub-escala I, é importante destacar que as crianças de 4 anos em diante, já possuem maior independência, facilitando assim a operacionalização de atividades de rotina. Além disso, com exceção das instituições filantrópicas, as demais pré-escolas atendem em período parcial, aproximando-se do modelo do ensino fundamental (Kramer, 1995; Kuhlmann, 2000), o que diminui consideravelmente as atividades de rotina, especialmente banho e sono, excluídas da avaliação.

Os escores mais baixos foram atribuídos às sub-escalas VI-Desenvolvimento social e II-Mobiliários e materiais para as crianças. Em relação à subescala VI, podemos considerar algumas questões sócio-culturais que, pela ECERS, são indicadores de baixa qualidade, tais como no item 28 , que prevê um espaço para as crianças brincarem sozinhas. Em geral, este aspecto é negligenciado, dado que o planejamento de tempo e espaço não permite a ocorrência deste tipo de atividade, principalmente pelo fato das crianças permanecerem em período parcial na instituição. Entretanto, concordamos com Weinstein (1987) quanto à importância da privacidade em instituições educacionais. Já que este é um ambiente em que as crianças passam juntas muitas horas do seu dia, é necessário que a organização espacial contemple diferentes tipos de espaço privado, permitindo à criança uma pausa inter-atividades ou mesmo um isolamento, total ou em pequenos subgrupos, como temos apontado em estudos anteriores (Campos-de-Carvalho, 2001; Campos-de-Carvalho \& Mingorance, 1999). Outro fator de grande importância, em geral ausente das instituições, é o trabalho com a perspectiva multi-cultural, previsto na sub-escala VI, através do oferecimento de materiais com variedade étnica e racial, como em bonecas, livros, painéis, etc.. Quanto à sub-escala II, as baixas pontuações podem ser explicadas pela organização espacial das salas que, na sua maioria, possuem apenas prateleiras, mesas e cadeiras, havendo ausência de brinquedos tais como bola, almofadas para descanso, centros de interesses claramente definidos, etc.. Estes itens possivelmente não são contemplados pela supervalorização das atividades de escrita/leitura, em detrimento das brincadeiras, tanto pela equipe como pelos pais, pois, como já dito, as pré-escolas brasileiras, em sua maioria, tomam como modelo o ensino fundamental (Kramer, 1995; Kuhlmann, 2000).

Concluindo, nos estudos aqui relatados, a ITERS e ECERS apresentaram altos índices de acordo entre avaliadores independentes, indicando sua precisão. Ademais, ambas as escalas discriminaram: a) os diversos tipos de instituição (filantrópica, municipal, universitária e privada), b) as turmas dentro de cada modelo e c) dentro de cada turma, as várias sub-escalas. Este último aspecto se mostra fundamental para a identificação de pontos deficitários para a implantação de futuras intervenções em uma turma específica, visando à melhoria de qualidade do atendimento.

Nossa proposição está sendo a utilização da ITERS para avaliar a qualidade de ambientes oferecidos para crianças de 0-30 meses e da ECERS, para turmas de 3 anos (ou de 30 meses) em diante, dada a maior especificidade da primeira escala para atendimento de crianças menores. Os próprios autores da ECERS já prevêm a não utilização de 10 itens (5/9 / 21 a $27 / 30$ ) para grupos de crianças de 0 a 9 meses e indicam, em outros quatro itens $(2 / 7 / 10 / 14)$, instruções alternativas excludentes para turmas de crianças até 9 meses e acima; alertam também que o avaliador, ao usar a escala com turmas de 1-2 anos, deve ter uma compreensão do que é apropriado para esta faixa etária, para poder diferenciar as descriçōes existentes na escala que sejam mais adequadas para turmas acima de 2 anos.

Ainda há necessidade de pesquisas futuras, anteriormente à publicação das escalas traduzidas, para aprofundar a análise da fidedignidade e da validade; esta última análise já se iniciou, embora não inclusa neste artigo. Furtado (2001) comparou se os critérios de qualidade da ECERS estariam próximos, ou não, dos critérios mínimos de qualidade aponta- 
dos em nove documentos oficiais brasileiros para credenciamento de instituições de educação infantil. Quanto à análise da validade da ITERS, Souza (2002) está analisando o parecer de duas especialistas brasileiras em educação infantil, sobre os itens contidos na escala (dados a serem relatados em futuros artigos); os resultados obtidos com as aplicações em três turmas da creche universitária também contribuem para uma análise da validade da escala. Ademais, para a validação dos instrumentos para nosso contexto sócio-cultural, ainda são necessários estudos comparativos da aplicação das escalas em várias regiões do país.

\section{Referências Bibliográficas}

Bairrão, J. (1997). Escala de avaliação do ambiente em educação infantil. Versão provisória para investigação, Universidade de Lisboa, Portugal.

Bairrão, J., Leal, T., Lima, I.A. \& Morgado, R. (1997). Educação pré-escolar. Em Ministério da Educação (Org.), A evolução do sistema educativo e o PRODEP (Estudos Temáticos-Vol. II, pp. 21110). Lisboa: Ministério da Educação.

Batista, C.G. (1996). Observação do comportamento. Em L. Pasquali (Org.), Teoria e métodos de medida em ciências do comprtamento (pp. 277303). Brasília: Inep.

Brasil (1988). Constituição da República Federativa do Brasil. Brasília.

Brasil (1996). Lei de Diretrizes e Bases da Educação Nacional. Brasília.

Campos, M.M. (1992). Child care in Brazil. Em M.E. Lamb, K.J. Stenberg, C.P. Hwang \& A.G. Broberg (Orgs.), Child care in context (pp. 479508). Hillsdale: Erlbaum.

Campos-de-Carvalho, M.I. (2001). O porquê da preocupação com o ambiente físico. Em M.C. Rossetti-Ferreira, A.M. Mello, T. Vitória, A. Gosuen \& A.C. Chaguri (Orgs.), Os fazeres na educação infantil (pp. 155-157). São Paulo: Cortez.

Campos-de-Carvalho, M.I. \& Mingorance, R.C.
(1999). Zonas circunscritas e ocupação do espaço por crianças pequenas em creche. Revista Interamericana de Psicología, 33(2), 67-89.

Campos-de-Carvalho, M.I. \& Rossetti-Ferreira, M. C. (1993). Importance of spatial arrangements for young children in day care centers. Children's Environments, 10(1), 19-30.

Dessen, M.A., \& Murta, S.G. (1997). A metodologia observacional na pesquisa em psicologia: Uma visão crítica. Cadernos de Psicologia, 1, 47-60.

Furtado, R.A. (2001). Avaliação de ambientes educacionais coletivos para pré-escolares. Dissertação de Mestrado, Universidade de São Paulo, Ribeirão Preto.

Furtado, R.A. \& Campos-de-Carvalho, M.I. (2000). Avaliação de ambientes educacionais coletivos para pré-escolares. Livro de artigos do III Seminário de Pesquisa do Programa de Pós-Graduação em Psicologia da Faculdade de Filosofia, Ciências e Letras de Ribeirão Preto/USP, Tomo II, 108-115.

Góis, A. (2000). 55\% das crianças estão em creches ilegais. Folha de São Paulo, São Paulo, 2 de jutho de 2000.

Harms, T. \& Clifford, R.M. (1980). Early Childhood Environment Rating Scale. New York: Teachers College Press.

Harms, T., Cryer, D.R. \& Clifford, R.M. (1990). Infant/Toddler Environment Rating Scale. New York: Teachers College Press.

Katz, L.G. (1998). Cinco perspectivas sobre qualidade. Em Ministério da Educação/ Departamento da Educação Básica (Ed.), Qualidade e projecto na educação pré-escolar (pp. 15-40). Lisboa: Editorial do Ministério da Educação.

Kramer, S. (1995). A política do pré-escolar no Brasil: $A$ arte do disfarce. São Paulo: Cortez.

Kuhlmann, M. (2000). História da educação infantil brasileira. Revista Brasileira de Educação, 14, 5-17.

Melhuish, E.C. (2001). The quest for the quality in 
early day care and preschool experience continues. International Journal of Behavioral Development, 25(1), 1-6.

Merisse, A. (1997). Origens das instituições de atendimento à criança: $O$ caso das creches. Em A. Merisse (Org.), Lugares da infância e reflexões sobre a história da criança na fábrica, creche e orfanato (pp. 25-51). Assis: Editora Artes e Ciência.

Ministério da Educação e do Desporto. (1998). Subsídios para Regulamentação e Credenciamento das Instituições Infantis, 1.Brasília: Secretaria de Educação Fundamental.

Oliveira, M.A. de (2000). Avaliação de ambientes coletivos para crianças pequenas. Monografia de Conclusão do Programa Especial de Bacharelado da Faculdade de Filosofia, Ciências e Letras de Ribeirão Preto, Universidade de São Paulo, Ribeirão Preto.

Pascal, C. \& Bertram, T. (1999). Desenvolvendo a qualidade em parcerias - Nove estudos de caso (A. M. Chaves, Trad.). Porto: Porto Editora.

Pasquali, L. (1996). Medida psicométrica. Em L. Pasquali (Org.), Teoria e métodos de medida em ciências do comportamento (pp. 73-115). Brasília: Inep.

Piotto, D.C., Chaguri, A.C., Mello, A.M., Silva, A.P.S., Eltink, C., Yazlle, C.H., Carniel, I.C., Sordi, G., Baldin, L.S.A., Frederick, M.I.B., Morais, R., Besani, V. \& Rossetti Ferreira, M.C. (1998). Promoção da qualidade e avaliação na educação infantil: Uma experiência. Cadernos de pesquisa, 105, 53-76.

Rosemberg, F. (1995). A criação de filhos pequenos: Tendências e ambigüidades contemporâneas. Em I. Ribeiro \& A.C.T. Ribeiro (Orgs.), Família em processos contemporâneos: Inovações culturais na sociedade brasileira (pp. 167-190). São Paulo: Loyola.

Sommer, B. \& Sommer, R. (1997). A Practical guide to behavioral research: Tools and techniques. New York: Oxford University Press.
Souza, T.N. (2002). Busca de qualidade em ambientes educacionais coletivos para crianças de 0 30 meses: Um estudo sobre a Infant/Toddler Environment Rating Scale. Qualificação de Mestrado, Universidade de São Paulo, Ribeirão Preto.

Tietze, W., Bairrão, J., Leal, T.B. \& Rossbach, H. (1998). Assessing quality characteristics of center-based early childhood environments in Germany and Portugal: A cross-national study. European Journal of Psychology of Education, XII (2), 283-298.

Tietze, W., Cryer, D., Bairrão, J., Palacios, J. \& Wetzel, G. (1996). Comparisons of observed process quality in early child care and education programs in five countries. Early Childhood Research Quarterly, 11, 447-475.

Weick, K.E. (1968). Systematic observational methods. Em L. Gardner \& A. Elliot (Eds.), Handbook of social psychology (Vol. II, pp. 357-451). Massachusetts: Wesley.

Weiner, I.B. (1991). Editor's note: Interscorer agreement in Rorschach research. Journal of Personality Assessment, 56, 1.

Weinstein, C.S. (1987). Designing preschool classrooms to support development: Research and reflection. Em C. S. Weinstein \& T. G. David (Eds.), Spaces for children - The built environment and child development (pp. 159-185). New York: Plenum.

\section{Apoio FAPESP e CNPq}

